\title{
Social Support Associated with Condom Use Behavior Among Female Sex Workers in Iran
}

\author{
Zahra Jorjoran Shushtari ${ }^{1}$. Ali Mirzazadeh ${ }^{2,3} \cdot$ SeyedAhmad SeyedAlinaghi ${ }^{4} \cdot$ Seyed Ali Hosseini ${ }^{1} \cdot$ Homeira Sajjadi $^{5}$. \\ Yahya Salimi ${ }^{6} \cdot$ Tom A. B. Snijders ${ }^{7,8}$
}

Accepted: 8 August 2021 / Published online: 2 September 2021

(c) International Society of Behavioral Medicine 2021

\begin{abstract}
Background Despite the widespread knowledge about social support and health, there is little information about the association between social support and HIV risk behaviors such as condom use among female sex workers (FSWs) in Iran. This study aimed to determine the association between social support and frequency of condom use among FSWs in Tehran, Iran. Methods Using mixed sampling methods, we recruited 170 FSWs in Tehran in 2017. We measured self-reported social support by face-to-face interviews using a standardized questionnaire. Linear regression was used to assess the association between socio-demographic characteristics (age, education level, marital status, and place of living), transactional sex characteristics (age at first transactional sex and frequency of transactional sex in the last month), HIV knowledge, social support network characteristics (social network size, duration of tie, intimacy, social support), and condom use behavior.

Results Of the total of 1193 persons in FSW's social networks, $615(51 \%)$ were sexual partners, $529(44 \%)$ were peer sex workers, and $36(5 \%)$ were family members. The participants perceived moderate social support from sexual partners, low from peer sex workers, and very low from family members. Adjusted for individual and other network characteristics, peer sex worker social support $(b=0.28,95 \% \mathrm{CI} 0.06,0.50)$, and family support $(b=1.12,95 \% \mathrm{CI} 0.028,2.23)$ were significantly associated with condom use.

Conclusion Family and peer sex worker social support are associated with condom use, but less strongly than HIV knowledge or place of living. However, very few FSWs are socially connected with families. Interventions to promote condom use among this vulnerable population should also consider social and familial support.
\end{abstract}

Keywords Social support $\cdot$ HIV risk behavior $\cdot$ Condom use $\cdot$ HIV $\cdot$ Female sex workers

\section{Introduction}

Currently, HIV prevention is one of the most important public health concerns and priorities in Iran [1,2]. HIV prevalence is low in the general population $(0.08 \%)$ in Iran, but high among vulnerable groups, specifically, injecting drug users $(13.8 \%)$ and sex workers $(4.5 \%)$ [1, 3, 4]. In response to this concentrated epidemic, the government has focused prevention activities on these important at-risk populations [1]. Sex work is illegal in Iran like many other countries, but Iran does not have a harsher legal and policy environment against FSWs. As is the case in most of the world, selling sex is against the law in Iran. By statute, prostitution

Seyed Ali Hosseini

seyedalihosseini1@outlook.com

Extended author information available on the last page of the article is punishable by whipping, and under some circumstances, the death sentence is possible [5]. These punishments are rarely applied, except when other criminal offenses were concurrently committed. In our national survey in 2015 , $14.8 \%$ of FSWs reported arrest and $6.8 \%$ incarceration in the past year $[6,7]$. This rate of incarceration is lower than in some other countries [8], including Canada (26.8\%) [9] and Mexico (49.0\%) [10]. Pre- and extra-marital sex are also illegal in Iran and have a bearing on what is considered to be sex work. The HIV epidemic has created a protected sociopolitical space in which Iranian health providers can deliver services for "vulnerable women" (i.e., FSWs, homeless women, women who use drugs) [11-13]. Since 2010, there are over 60 community-based organizations (CBO) in Iran, funded by the Ministry of Health, to provide harm reduction to FSWs (e.g., HIV testing, sexual health education, condoms) [11]. These programs form the basis of past studies 
about FSWs and help addressing their needs throughout the country $[2,11]$. Although these efforts in Iran are beneficial for HIV prevention by increasing the access of at-risk groups including FSWs to health care and HIV prevention services $[1,14]$, they do not address how social and contextual factors play a role in HIV prevention and transmission.

Historically, sex work was permitted and less stigmatized before 1979 in Iran [15]. However, since the Islamic revolution of Iran (1979), sex work has been considered as illegal and associated with high social stigma and marginalization. Since the existence of sex work was denied by the government until recently, there is little information about this vulnerable group [16]. The evidence shows that in Iran, FSWs are mainly street-based and find their clients via streets, shopping malls, parks, and public transit [4]. According to a size estimation study, there were $228,700 \mathrm{FSWs}$ (95\% CI 153,500-294,300) in Iran in 2012 [17]. The negative attitudes in Iranian society regarding sex work put FSWs at the risks of violence, refusal of contact, and social isolation. FSWs, being the second largest at-risk group for HIV in Iran $[1,2]$, play a major role in the HIV epidemic due to their HIV risk behaviors such as unsafe sex, drug or alcohol use before or with sex, and having multiple sexual partners. Not only are they at risk themselves for HIV but also their sexual partners are at risk, and these can be a bridge group to transmit HIV to the general population [13]. According to previous studies in Iran, most FSWs had sufficient HIV knowledge and knew that condom use is a method to reduce risk of HIV transmission; however, only few of them used condoms with their paying and non-paying partners [18]. A survey in 14 cities in Iran showed that in spite of the availability of free HIV testing services for FSW, 65\% of them had not tested for HIV in the past year [3].

Condom use is one of the effective strategies that may help prevent HIV infection for FSWs and their clients [19-21]. Condom use has worldwide prevented nearly 50 million new HIV infections since the onset of the HIV epidemic [22]. Several investigators explored many determinants of condom use by FSWs [23-26]. A qualitative study in Tehran, Iran, found that the low level of condom use among FSWs is due to a variety of individual, structural, and cultural factors [27]. This study showed that the main individual, structural, and cultural barriers of condom use among FSW in Tehran were [1] lack of knowledge about HIV/AIDS, seeing condom use as a sign of love and loyalty, drug use, fatalism, and disappointment in life with low expectations for the future; [2] sexual partner violence, partner's desire, problems with condom availability, and price; and [3] feeling embarrassed to obtain condoms, following the example of peer sex workers and low condom use among friends [27]. Two studies in the Dominican Republic and in the Philippines showed that FSWs who had fewer intimate relationships and less frequent contact with their peers were less likely to use condoms [28, 29]. This evidence suggests that it is imperative to consider, in addition to individuallevel factors, broader structural or contextual factors that are involved in condom use $[24,30]$. Social network characteristics are important predictors of HIV-risk behaviors such as unprotected intercourse. One of the important determinants of unprotected intercourse at the network level is social support [24, 26, 31]. The social support network is comprised of interpersonal ties that can provide assistance among members of a social network [32]. Social support is a substantial aspect of psychological adjustment for coping with multiple harms and stressors [33, 34]. Personal networks change as a consequence to major life course events/crises such as loss and disease [35-37]. Such events may change social networks in terms of size, composition, and social support [38, 39]. Literature has shown that social networks are smaller for high-risk populations such as people living with HIV, injecting drug users, and men who have sex with men, compared to the general population [32, 40-42]. Regarding FSWs, social stigma and discrimination can have effects on size and composition of their social network. This may directly affect social support provided by network members [43]. Positive support ties can improve self-efficacy and promote efforts to negotiate safer behaviors [44], and interventions to strengthen those positive relationships could improve health outcomes for at risk populations [45]. A qualitative study in China revealed that "Laoxiang (hometown) sisters," FSWs who originate from the same villages, create solidarity and support for condom use and HIV testing among the FSWs [46]. Also, a social network study among 454 establishmentbased FSWs in China showed that perceived social support from gatekeepers was associated with condom communication with clients and stable partners [47].

Despite the growing body of literature on the concept of social support [32, 48], there is a lack of information about the role of social support for condom use as a HIV-related risk-reducing behavior among FSWs in Iran. We aimed to study the effects of social support, in the context of other personal and social factors, on the frequency of condom use by FSWs in Tehran, Iran. Our hypothesis was that social support is associated with condom use behavior of FSWs. A conceptual framework summarizing the role of individual and social support network characteristics in condom use among FSWs was based on previous studies of the effects of various factors on unprotected intercourse and condom use [49-52]. A systematic review showed that social network characteristics such as frequency of contact, intimacy, and social support are related to condom use by FSWs [52]. We employ a conceptual ordering going from individual background characteristics, to relations with the sexual network (regular sexual partners and clients), and from there to the role of supportive network ties with peer sex workers and family members. Concerning the latter, it was thought 
that supportive network members, next to sexual partners, may also influence FSW's safe sex behaviors. For example, positive ties to social support network members can support efforts to negotiate safer behaviors [53, 54]. Variables in these three groups include first, socio-demographic and transactional sex characteristics including age, education level, marital status, place of living, age at first transactional sex, frequency of transactional sex in the last month, and HIV knowledge; second, sexual network characteristics including network size, duration of tie, intimacy, and sexual partner support; and third, family support and peer sex worker social support. These three groups reflect a conceptual ordering without causal assumptions $[55,56]$.

\section{Methods}

\section{Study Design}

This cross-sectional study was conducted from January to June 2017 among 170 FSWs in Tehran. Since the studied population constitute a hidden and hard to reach population, snowball, convenience, and targeted sampling methods, being successful methods to recruit "hidden" populations in previous studies $[57,58]$ were used to enlist participants. We approached and invited 178 FSWs, of whom 8 did not agree to participate. Therefore, $170 \mathrm{FSWs}$ participated in our study.

\section{Participants and Network Members}

Recruitment of participants was facilitated by a peer recruiter and staff of a drop-in center (DIC). Eligibility criteria were being over 16 years old, having had sex for money in the last 6 months, identifying themselves as sex workers, and willingness to participate in the study. We started recruitment of the participants by following, as far as feasible, the strategy of respondent-driven sampling [59]. To initiate the sampling process, six index participants were chosen among FSWs who attended the DICs, lived in parks, and had access to some home groups selected by targeted sampling. We asked them to introduce their peer sex worker friends who were named as their network members, and gave coupons for these peer sex worker friends if they would participate in the study. Each coupon for the friends included ID number, aim of the study, amount of incentive, and date and place of visit for the interview. Each of the participants was given $\$ 3$ as a small primary incentive for participating in the study and completing the interview; as well as a secondary small incentive, again of $\$ 3$, if they had introduced their peer sex worker friends. This process continued mostly until three waves. After the third wave, the introductions of peer sex worker friends from the participants were sporadic and limited. Some participants introduced just one or two peer sex worker friends who were named as network members and some introduced only other FSWs who were not named as their network members. We also recruited some FSWs who attended DIC services by convenience sampling, and also by outreach teams from homes, streets, and parks. We continued the sampling process until it was difficult, and lasted a long time, for our peer recruiter and DIC staff members to find a new FSW.

\section{Data Collection}

Data were collected through face-to-face structured interviews by a peer trained interviewer. An investigator-constructed questionnaire was used, after assessing its face validity, content validity, scalability, and reliability. Each interview usually lasted around $45 \mathrm{~min}$.

The questionnaire had two main parts containing individual and network information. In an egocentric network survey, respondents provide information about their network members. This information can be used to assess network characteristics and test hypotheses [60].

In the present study, egocentric network information was obtained for each participant and used to assess the effect of social support from network members on the participants' condom use. We asked participants to nominate up to 20 persons with whom they had had meaningful and close contacts during the past 30 days (name generator). For these nominated persons, we asked some questions about their socio-demographic characteristics and the content of their interaction with the FSW including duration of contact, intimacy, and social support. The sexual network was defined as the set of nominated persons with whom they had had sex in the past 30 days. The peer network was defined as the set of nominated sex worker friends with whom they had had communication in the past 30 days. The family network was defined as parents, siblings, children, and other relatives with whom they had been in contact in the past 30 days.

\section{Measurements}

\section{Socio-demographic Characteristics}

Socio-demographic profiles were assessed based on age, education level, marital status, and place of living. Age was recorded as a continuous variable. Current marital status was recorded as single, married, divorced, concubine, or widowed. For the regression analysis, this was dichotomized as never married and married, because otherwise some categories would be too small. The married category includes married, concubine, divorced, and widowed. Place of living was categorized as homeless, living in the home of others, and personal home. 


\section{Transactional Sex Characteristics}

For assessing transactional sex characteristics, participants were asked to report their age at first transactional sex and the frequency of transactional sex in the last month. Age at first transactional sex was categorized as before 18 years, between 18 and 30 years, and older than 30 years. Frequency of transactional sex in the last month was recorded as a count variable.

\section{HIV Knowledge}

HIV knowledge was measured by a 14-item questionnaire which was established in Iran [61]. The questionnaire was pilot-tested with 28 FSWs in Tehran. Cronbach's alpha for this scale was 0.86 . The total score of knowledge was transformed to a scale of 0 to 100 . Higher scores mean more knowledge about HIV.

\section{Social Network Variables}

Social network size, the number of network members, was recorded as a count variable. To assess duration of the tie, we asked the participants "For how long have you known this person (in months)?" The intimacy of the relationship between the participants and social network members was determined with a five-point Likert response, with categories very close, close, somewhat close, distant, and very distant. Since the dependent variable was at the ego or FSW level $(N=170)$, characteristics of the relationships were aggregated to the FSW level by averaging [62].

\section{Social Support}

Social support was assessed for each nominated network member by an investigator-constructed questionnaire with five items. Example items are "How much does this person make you feel respected or admired?", "If you need money and he can afford it, how much does this person usually help you?", and "If you need a place to stay at night, how much does this person usually help you?" Each question had a five-point Likert response with categories very low, low, somewhat, much, very much. According to the psychometric characteristics [63-66], the content validity indices clarity, relevance, and comprehensiveness were $98 \%, 95 \%$, and $93 \%$, respectively. The reliability of the social support questionnaire was pilot-tested prior to the final implementation in this study. Cronbach's alpha and intra-class correlation for this scale were $81 \%$ and $85 \%$, respectively. Mokken scale analysis was used to assess scalability and unidimensionality of the questionnaire [67]. All items had Hi coefficients greater than 0.5, indicating a strong scale.
Table 1 Characteristics of female sex workers $(N=170)$, Tehran, 2017

\begin{tabular}{lll}
\hline Characteristics & & $N(\%)$ or mean (SD) \\
\hline Age & & $34.0(7.6)$ \\
Current marital status & Single & $28(16 \%)$ \\
& Married & $22(13 \%)$ \\
& Divorced & $100(59 \%)$ \\
& Concubine & $11(7 \%)$ \\
& Widowed & $9(5 \%)$ \\
Education level & Illiterate & $5(3 \%)$ \\
& Just reading and writing & $2(1 \%)$ \\
& Primary education & $18(10 \%)$ \\
& Secondary education & $68(40 \%)$ \\
Current place of living & High school or Diploma & $71(42 \%)$ \\
& University degree & $6(4 \%)$ \\
Age at first transactional sex (year) & Homeless & $47(28 \%)$ \\
Frequency of transactional sex in the last & Living in others' home & $54(32 \%)$ \\
month & Personal home & $69(40 \%)$ \\
HIV knowledge & $<18$ & $18(11 \%)$ \\
\hline
\end{tabular}


Table 2 Aggregated social network characteristics of the participants, Tehran, 2017. $N=$ number of network members. For the Family Network, average size, duration, and intimacy are given only for the 24 respondents mentioning at least one family member

\begin{tabular}{llcr}
\hline Characteristics & Mean $(\mathrm{SD})$ & Median $(\mathrm{IQR})$ & Min-max \\
\hline All social networks $(N=1193)$ & $7.7(\mathrm{SD}=1.5)$ & $8(2.0)$ & \\
Sexual network $(N=615)$ & & & \\
Network size & $3.6(\mathrm{SD}=1.0)$ & $4.0(1.0)$ & $1-8$ \\
Duration of tie (months) & $48(\mathrm{SD}=32)$ & $44[26]$ & $2-192$ \\
Intimacy & $4.2(\mathrm{SD}=0.8)$ & $4.3(1.28)$ & $0-5$ \\
Sexual partner' social support & $2.7(\mathrm{SD}=1.3)$ & $3.0(2.0)$ & $1-6$ \\
Peer sex worker network $(N=529)$ & & $3.0(1.0)$ & $1-261$ \\
Network size & $3.1(\mathrm{SD}=0.9)$ & $35[46]$ & $1-4$ \\
Duration of tie (months) & $56(\mathrm{SD}=54)$ & $1.8(1.7)$ & $0-6$ \\
Intimacy & $2.0(\mathrm{SD}=0.9)$ & $0(1.7)$ & $1-3$ \\
Peer 'social support & $0.8(\mathrm{SD}=1.1)$ & & $1.0(0)$ \\
Family network $(N=30)$ & & $315(117)$ & $1.0(1.2)$ \\
Network size & $1.3(\mathrm{SD}=0.5)$ & $0(0)$ & $1-4$ \\
Duration of tie (months) & $303(\mathrm{SD}=108)$ & $0-1$ \\
Intimacy & $1.7(\mathrm{SD}=1.0)$ & $0.3(\mathrm{SD}=0.4)$ & \\
Family social support & & & \\
\hline
\end{tabular}

Social support from each of the parts of the personal network (sexual, peers, family) was measured as the number of network members who gave adequate or more support, where "adequate" was defined as an average value of 3 or more on this scale.

\section{Condom Use}

The dependent variable was frequency of condom use, which was considered as HIV risk behavior. The frequency of condom use was measured as a sum score for an investigatorconstructed questionnaire with 17 questions each on a fivepoint Likert response, with categories $1=$ never, $2=$ rarely, $3=$ sometimes, $4=$ often, and $5=$ always. Example items are "How often do you use condoms in sexual relationships with your clients?" and "How much do you insist on condom use even if your partner did not want to use a condom?" The reliability of the questionnaire was pilot-tested. The attainable score range is 17-85. Higher scores indicate that the attitude and behaviors of FSWs are positive about condom use and frequently use it in their sexual relationships [68]. Cronbach's alpha and the intraclass correlation for this scale were 0.89 and 0.83 , respectively. Mokken scale analysis was used to assess scalability and uni-dimensionality of the questionnaire [67]. The Loevinger $H$-coefficient for the scale was larger than 0.5 , characterizing it as strong scale. The sum scale had a strongly skewed distribution, and therefore the dependent variable was defined as the square root of (sum scale-17).

\section{Ethical Considerations}

Since sex work is illegal in Iran [69], verbal informed consent was obtained from all eligible participants. The ethics committee of the University of Social Welfare and Rehabilitation Sciences approved the study protocol (IR.USWR. REC.1394.187).

\section{Statistical Analysis}

Pearson correlations were calculated for getting a basic insight into patterns of association of all variables in the data (Appendix 1). The distributions of the scores were assessed carefully for missing values and outliers, which may affect both the comparison of means and the interpretation of correlation coefficients in bivariate analysis and regression analysis.

Next, we conducted a linear regression analysis in three steps, with successively larger sets of explanatory variables, and condom use behavior as the dependent variable. In order to select which variables could be included as explanatory variables, first we listed the variables based on the literature review and available evidence; then, we explored the associations between all numerical independent variables and also between dependent and independent variables by correlations. Independent variables were entered into the regression model in three groups, reflecting the conceptual framework ordering going from individual background characteristics to the sexual network characteristics, interpreted as risk network ties (regular sexual partners and clients), and then to the role of peer sex worker support and family support, interpreted as supportive ties. Place of living and age at first transactional sex variables were entered into the model as dummy variables; the baseline level was the first category. 
Table 3 Regression analysis of condom use behavior among 170 FSWs in Tehran, 2017

\begin{tabular}{|c|c|c|c|c|}
\hline \multirow[t]{3}{*}{ Independent variables } & \multicolumn{4}{|c|}{ Dependent variable (condom use behavior) } \\
\hline & \multirow{2}{*}{$\begin{array}{l}\text { Unadjusted coefficient } \\
(95 \% \mathrm{CI})\end{array}$} & \multirow{2}{*}{$\begin{array}{l}\text { Model } 1 \\
\text { Adjusted coefficient } \\
(95 \% \mathrm{CI})\end{array}$} & \multirow{2}{*}{$\begin{array}{l}\text { Model } 2 \\
\text { Adjusted coefficient } \\
(95 \% \mathrm{CI})\end{array}$} & \multirow{2}{*}{$\begin{array}{l}\text { Model } 3 \\
\text { Adjusted coefficient } \\
(95 \% \mathrm{CI})\end{array}$} \\
\hline & & & & \\
\hline Age & $0.066 * * *(0.030,0.102)$ & $0.037(-0.002,0.078)$ & $0.024(-0.013,0.061)$ & $0.022(-0.015,0.058)$ \\
\hline Education level & $0.31 *(0.02,0.60)$ & $0.44 * * *(0.18,0.69)$ & $0.28 *(0.03,0.54)$ & $0.31 *(0.06,0.55)$ \\
\hline \multicolumn{5}{|l|}{ Place of living } \\
\hline \multicolumn{5}{|l|}{ Homeless (ref.cat) } \\
\hline Living in others' house & $0.67(-0.05,1.39)$ & $1.09 * * *(0.47,1.72)$ & $0.72 *(0.14,1.31)$ & $0.69 *(0.12,1.26)$ \\
\hline Personal home & $1.12 * * *(0.44,1.80)$ & $1.20 * * *(0.60,1.80)$ & $1.15^{* * *}(0.60,1.70)$ & $1.06 * * *(0.53,1.60)$ \\
\hline \multicolumn{5}{|l|}{$\begin{array}{l}\text { Age at first transactional } \\
\text { sex (year) }\end{array}$} \\
\hline \multicolumn{5}{|l|}{$<18$ (ref.cat) } \\
\hline $18-30$ & $0.32(-0.53,1.75)$ & $0.53(-0.13,1.20)$ & $0.46(-0.16,1.07)$ & $0.24(-0.36,0.85)$ \\
\hline$\geq 30$ & $1.33 * *(0.51,2.15)$ & $1.08 * *(0.40,1.75)$ & $0.85^{* *}(0.23,1.48)$ & $0.74 *(0.14,1.35)$ \\
\hline $\begin{array}{l}\text { Frequency of transactional } \\
\text { sex in the last month }\end{array}$ & $-0.18^{* * *}(-0.23,-0.13)$ & $-0.15^{* * *}(-0.20,-0.11)$ & $-0.11 * * *(-0.16,-0.06)$ & $-0.09 * * *(-0.14,-0.04)$ \\
\hline HIV knowledge & $0.03 * * *(0.02,0.04)$ & $0.03 * * *(0.01,0.04)$ & $0.03 * * *(0.02,0.04)$ & $0.03 * * *(0.01,0.04)$ \\
\hline Sexual network size & $-0.39 * * *(-0.67,-0.11)$ & & $-0.05(-0.32,0.22)$ & $-0.07(-0.33,0.19)$ \\
\hline $\begin{array}{l}\text { Duration of tie with sexual } \\
\text { partners (year) }\end{array}$ & $-0.25^{* * *}(-0.35,-0.15)$ & & $-0.10^{*}(-0.19,-0.02)$ & $-0.11 *(-0.24,-0.02)$ \\
\hline $\begin{array}{l}\text { Intimacy with sexual } \\
\text { partners }\end{array}$ & $-1.27 * * *(-1.59,-0.94)$ & & $-0.74 * * *(-1.16,-0.31)$ & $-0.53 *(-0.96,-0.11)$ \\
\hline $\begin{array}{l}\text { Sexual partners' social } \\
\text { support }\end{array}$ & $-0.54 * * *(-0.73,-0.34)$ & & $0.00(-0.25,0.26)$ & $-0.01(-0.26,0.24)$ \\
\hline Peers' social support & $0.79 * * *(0.54,1.04)$ & & & $0.28 *(0.06,0.50)$ \\
\hline Family social support & $1.93 * * *(0.41,3.44)$ & & & $1.12 *(0.02,2.23)$ \\
\hline Adjusted $R$-squared & - & 0.46 & 0.55 & 0.59 \\
\hline
\end{tabular}

${ }^{*} p$-value $\leq 0.05 ; * *$-value $\leq 0.01 ; * * * p$-value $\leq 0.001$

Since the dependent variable, condom use, was at the ego or FSW level $(N=170)$, intimacy and duration of the network ties were aggregated to the level of FSW by averaging [62]. Duration was transformed to years. The data was analyzed by the R software [70]. $P$-values less than 0.05 were regarded as statistically significant. To aid interpretation, effect sizes $\beta$ were also calculated as standardized regression coefficients. For categorical variables, the standardized regression coefficient was defined as the standardized regression coefficient of the numerical variable with values given by the regression coefficients of the categories.

\section{Results}

Mean age of the participants was 34 years $(\mathrm{SD}=7.6)$ (Table 1). Many of the participants $(71,42 \%)$ had a high school or diploma degree. Most of the participants were divorced $(100,59 \%)$, and many reported living in their personal home $(51,42 \%)$. The mean score of HIV knowledge of the FSWs was $78(\mathrm{SD}=19)$.

The participants named a total of 1193 people as their social network members (Table 2). All mentioned at least one member of the sexual network and at least one peer friend; 24 mentioned at least one family network member. Of the social network members, $615(51 \%)$ were sexual partners, $529(44 \%)$ were peer friends, $30(5 \%)$ were family members, and 19 were regular friends. The mean size of the social network was 7.0 $(\mathrm{SD}=1.5, \mathrm{Min}=2, \mathrm{Max}=11)$. The mean sexual network size was $3.6(\mathrm{SD}=1.0)$, while the mean family network size, for those who mentioned at least one family member, was $1.25(\mathrm{SD}=0.5)$. The proportion of sexual partners in the FSWs' network was slightly more than $0.5(N=615,51 \%)$. The number of persons providing at least adequate social support in the sexual network ranged from 0 to 7 (mean $=2.8, \mathrm{SD}=1.5$ ), in the peer network from 0 to 6 (mean $=0.7, \mathrm{SD}=1.2$ ), and in the family network from 0 to 
Table 4 Standardized coefficient estimates of model 3 in the regression analysis of condom use behavior among 170 FSWs in Tehran, 2017

\begin{tabular}{lc}
\hline Independent variables & $\begin{array}{l}\text { Dependent variable } \\
\text { (condom use) } \\
\text { Model 3 } \\
\text { Standardized coefficient }\end{array}$ \\
\hline Age & 0.08 \\
Education level & 0.16 \\
Place of living & 0.23 \\
Age at first transactional sex & 0.16 \\
Frequency of transactional sex in the last & -0.25 \\
$\quad$ month & 0.26 \\
HIV knowledge & -0.04 \\
Sexual network size & -0.16 \\
Duration of tie with sexual partners & -0.22 \\
Intimacy with sexual partners & -0.01 \\
Sexual partners' social support & 0.16 \\
Peers' social support & 0.12 \\
Family social support &
\end{tabular}

$1($ mean $=0.3, \mathrm{SD}=0.5)($ Table 5$)$. Reasoning that receiving support from a high number of others does not give additional benefits, for the regression analysis, these numbers were truncated to 4 for the sexual network and to 3 for the peer network.

Outliers were found only in the frequency of transactional sex in the last month. This was truncated for the regression analysis by replacing the three values higher than 20 by 20 .

In the linear regression analysis (Table 3), Model 1 showed that education level was positively associated with condom use $(b=0.44,95 \%$ CI $0.18,0.69)$. FSWs who lived in other's home $(b=1.09,95 \%$ CI $0.47,1.72)$ and in their personal home $(b=1.20,95 \%$ CI $0.60,1.80)$ used condoms in their sexual relationships significantly more than homeless FSWs.

FSWs who initiated transactional sex after 30 years of age used condoms in their sexual relationships significantly more compared to those who initiated transactional sex before being 18 years old ( $b=1.08,95 \%$ CI $0.40,1.75)$. FSWs who reported more transactional sex in the last month used condoms significantly less in their sexual relationships ( $b=-0.15,95 \% \mathrm{CI}-0.20,-0.11)$. Model 1 also showed a positive association between HIV knowledge and condom use $(b=0.027,95 \%$ CI $0.014,0.039)$.

After adding sexual network characteristics in Model 2, the effects of level of education, place of living, age at first transactional sex, frequency of transactional sex in the last month, and HIV knowledge persisted. Moreover, Model 2 showed that average duration of the ties with sexual partners, average intimacy with sexual partners, and support from sexual partners after adjusting for individual characteristics of the respondents were negatively associated with condom use. A 1-year increase in average duration of the tie was significantly associated with 0.10 decline in condom use (Model 2). However, sexual network size was not significantly associated with condom use $(b=-0.005$, 95\% CI - 0.027, 0.026).

The last model, which included also the individual and social support network variables, indicated that not only individual characteristics of the FSWs and variables related to the sexual partners, but also social support from other parts of the network was significantly associated with condom use. In this model, social support from peer sex workers $(b=0.28,95 \%$ CI $0.06,0.50)$ and from family members ( $b=1.12,95 \%$ CI $0.02,2.23)$ showed significant associations with condom use. After adding peer and family support, support from sexual partners did not have a significant association with condom use.

The adjusted $R^{2}$ for Model 3 was 0.59 . The standardized coefficients are shown in Table 4.

From these it can be concluded that the most important variables for explaining condom use are for the FSW herself, her knowledge of HIV, and her place of living, and for her transactional sex, its frequency and the average intimacy with her sexual partners. Next in importance is her level of education, the age at which she started sex work, the average duration of her ties with sexual partners, social support from peers, and social support from family.

\section{Discussion}

Our cross-sectional analysis of 170 FSWs in Iran showed that education, housing status, age of first transactional sex, frequency of transactional sex, HIV knowledge, average duration of the tie with sexual partners, average intimacy with sexual partners, and social support from peer sex workers and from family members were associated with frequency of condom use over the past 30 days.

We found that on average FSWs perceived moderate social support from sexual partners, low from peer friends, and very low from family members. One explanation for this finding is that social networks of FSWs in Iranian society, where sex work is illegal, may be affected by the social stigma and the negative attitude of society to their work. FSWs often are rejected by their family and regular friends, or they may have run away, leaving their family and losing ties that might have been important sources of social support [53, 71-73]. Social stigma, criminalization, and isolation can lead to internalized low self-esteem which increases the likelihood of making risky decisions and behaving in risky ways [69]. 
Furthermore, FSWs may have difficulties in developing supportive relationship with their peer friends or co-workers because of potential competition and mutual distrust [74]. Also, most FSWs, due to fear of disclosing their activity and being arrested, are a mobile community with limited access to potential sources of support such as family members. The lack of supportive ties with regular friends, family members, and peer friends may exacerbate the dependency of FSWs on their sexual partners as providers of financial and emotional support, as well as drugs, especially in a context of low socioeconomic status, which exposes FSWs more strongly to risky behaviors and unsafe sex [75, 76].

One interesting finding was that different sources of social support influenced condom use by FSWs in different ways. In line with Tucker et al. [46, 76] and Qio et al., [76], we found that social support from peer friends was positively associated with condom use by FSWs. This positive association remained, although smaller in magnitude, when it was controlled for individual and other network characteristics. Peer ties among FSWs may create self-help groups and safe sexual behavior norms, promote linking with outreach group members and health care providers, and encourage HIV testing. Our findings also showed that although few FSWs were connected with families, family support was positively associated with their condom use. This finding is consistent with other studies suggesting that perceived support from family members may change attitudes of FSWs and motivate them to practicing safer sexual behaviors $[71,77,78]$. Also, the average number of peer friends was low, but nevertheless support from peer network members was positively associated with condom use by the FSWs. These findings highlight the important role of social support from family members as well as peer sex worker friends.

Additionally, our findings showed that perceived social support from sexual partners was negatively associated with condom use by the FSWs. This association was significant in the second model, but after adding family and peer sex worker social support, it was not significant in the final model. This important finding highlights the role of social support from family members and peer friends which may cancel out the negative effect of sexual partners' support on safe sex behaviors among FSWs. This finding differs from some previous studies [75, 79]. This difference may be due to that we considered the role of social support from family members and peer sex workers in our study, but the previous studies did not. Also, some difference in methodological aspects and social and cultural contexts might be the reason of this inconsistency between the studies. However, our findings showed that FSWs who had on average more intimate relationships with sexual partners reported less frequent condom use in their sexual relationships. One explanation for this finding is that a close and intimate relationship between the FSW and her sexual partner will go along with an affective and emotional bond in which the FSW trusts her partner and accepts his request not to use condoms. There is evidence that intimacy has linkages to trust, love, and empathy facets of the relationship with the sexual partner, which may decrease gender-based violence or sexual violence [80]. Therefore, to maintain the intimate relationship and to avoid violence and conflicts with her partner, the FSW may accept his requests for unsafe sex. This suggests the possibility of an educational intervention in this vulnerable population to train and inform FSWs about the importance of condom use even in relations with strong intimacy, and about the consequences of unsafe sex. It is not surprising that our findings showed HIV knowledge to be negatively associated with frequency of condom use [81, 82]. According to previous studies, having HIV knowledge may not be sufficient for safe sexual behaviors, as misconceptions about ways of HIV transmission and prevention are common among FSWs [83-85].

Our findings also indicate that place of living is significantly associated with frequency of condom use. FSWs who lived in another's house or in their personal home used condoms significantly more compared to homeless FSWs. This may be a consequence of poverty, unmet substantial needs, problems of daily life, drug use, and mental illness such as depression, experienced by homeless FSWs [86]. Homeless FSWs usually have more power inequality in their relationships than the general population, and are mainly dependent on getting income by selling sex to provide for their daily living and to obtain drugs, which in turn limits their power to negotiate about safe sex and protect themselves against sexual violence and other risks. Place of living is also related to social support because social support from others within the same household, especially family members, may alleviate problems of FSWs' daily life and motivate them directly and indirectly toward safe sexual behavior.

Our study had five main limitations. First, we used selfreport data. Therefore, our findings might be unreliable and subject to information bias. Second, we did not measure and account for the possible overlaps between the social networks of respondents, which might overestimate the overall social networks of FSW and have jeopardized independence assumptions for the linear regression. Third, no causal inferences can be drawn due to the cross-sectional design. Fourth, the study participants were recruited using nonrandom sampling methods from one city in Iran. Therefore, the findings may not be generalized to all FSWs in the country. Finally, fully understanding of the FSW's HIV risk is difficult, since we did not ask about their HIV status.

In spite of these limitations, this study provided important insights about social support from different groups, and its association with sexual behaviors among FSWs, 
which can be used for HIV intervention programs among FSWs. In summary, our findings highlight the low perceived social support for FSWs and the complexity of the influence of FSW's social and sexual network ties on condom use. According to our findings, increasing social support from peer sex workers, and also from family members, such as parents and siblings, may increase condom use among FSWs. Interventions to strengthen those positive and supportive relationships could be part of the fundamental strategies to develop HIV/AIDS prevention and control in this vulnerable population. Place of living and HIV knowledge are other important factors which are, even more strongly than social support, associated with frequency of condom use among the FSWs. This study emphasizes the importance of considering living conditions, HIV knowledge, and multiple dimensions of FSWs' social networks (with the distinction between social support from sexual connections, from family members, from peer sex workers, and from other friends) to improve our understanding of condom use by FSWs. In order to decrease the spread of HIV infection among FSWs, their network members, and the general population, future interventions should aim at strengthening relationships between FSWs and their network members, practically educating FSWs to reach out to their peers, and addressing gaps in their knowledge and attitudes toward sexual risk behaviors. Our findings also suggest that future interventions should focus on improving the relationship between FSWs and their family members to increase family social support, and on providing FSWs with a better and more stable place of living. Tables 5 and 6

Acknowledgements This paper is part of a $\mathrm{PhD}$ thesis from university of Social Welfare and rehabilitation Sciences, Tehran, Iran. The authors would like to show their gratitude to consultation centre for at risk women, Mikhak drop-in center, all the study participants, and also the University of California, San Francisco's International Traineeships in AIDS Prevention Studies (ITAPS), U.S. NIMH, R25MH064712, for their collaboration and contribution.

\section{Declarations}

Ethical Approval All procedures performed in studies involving human participants were in accordance with the ethical standards of the institutional and/or national research committee and with the 1964 Helsinki declaration and its later amendments or comparable ethical standards.

Informed Consent Informed consent was obtained from all individual participants included in the study.

Competing Interest The authors declare no competing interests.

\section{Appendix}

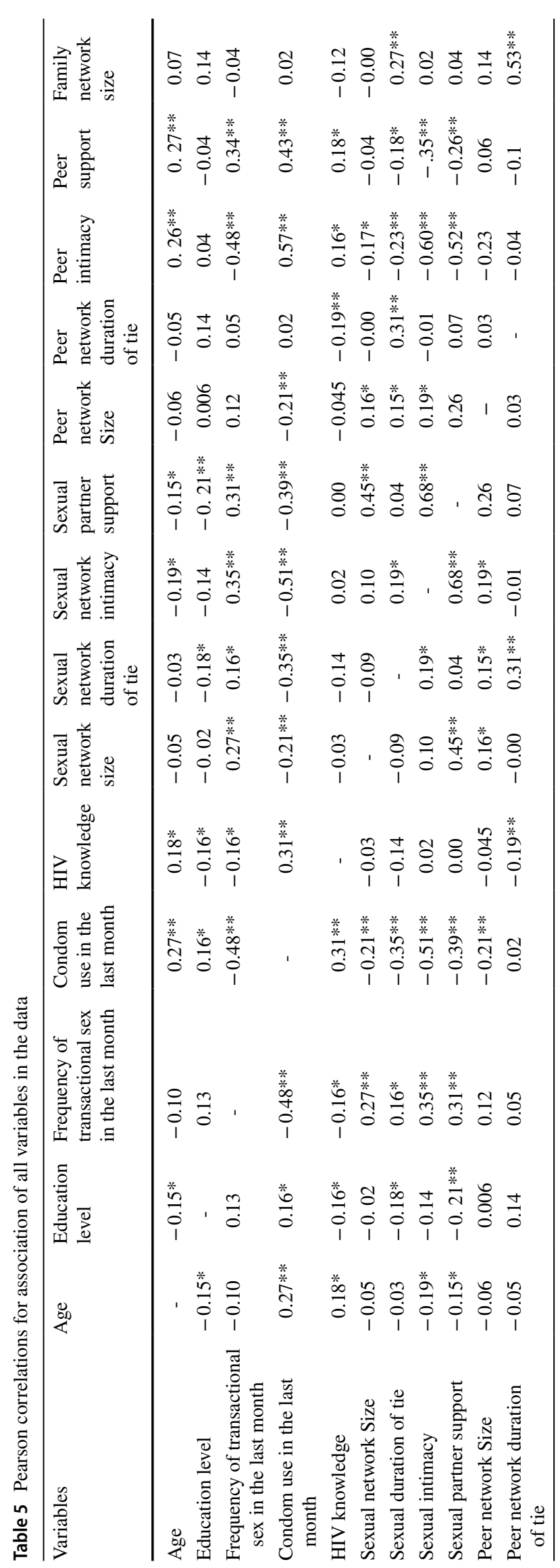




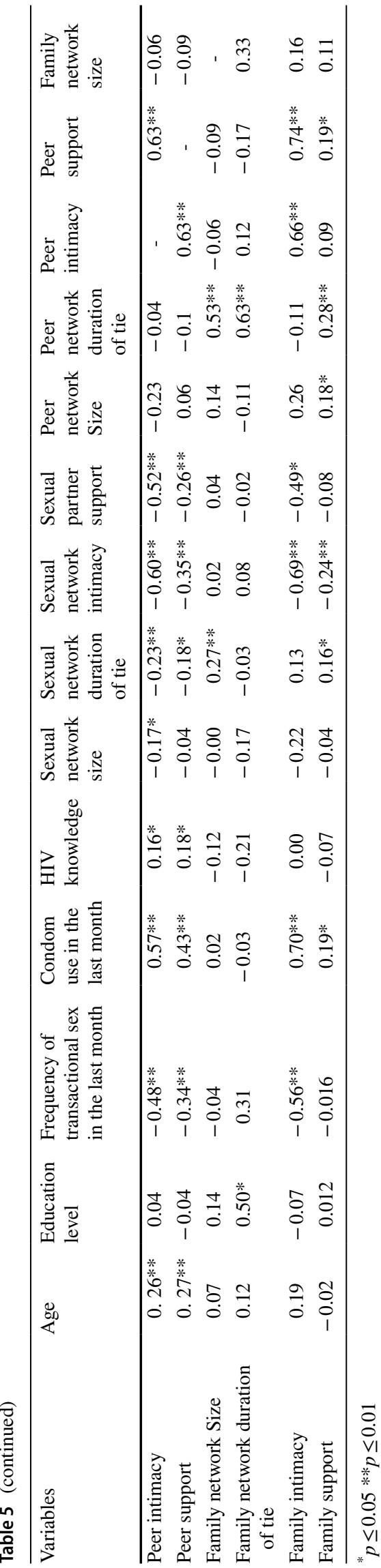

Table 6 Distribution of the number of persons providing at least adequate social support in the sexual, peer, and family network of the FSWs

\begin{tabular}{llll}
\hline $\begin{array}{l}\text { No. of person } \\
\text { in networks }\end{array}$ & Peer support & Sexual support & Family support \\
\hline 0 & 116 & 13 & 164 \\
1 & 16 & 26 & 6 \\
2 & 23 & 28 & 0 \\
3 & 9 & 33 & 0 \\
4 & 5 & 57 & 0 \\
5 & 0 & 10 & 0 \\
6 & 1 & 2 & 0 \\
7 & 0 & 1 & 0 \\
Total & 170 & 170 & 170 \\
\hline
\end{tabular}

\section{References}

1. National AIDS Committee Secretariat, Ministry of Health and Medical Education. Islamic Republic of Iran AIDS progress report: on monitoring of the United Nations General Assembly Special Session on HIV and AIDS. Tehran, Iran2015.

2. SeyedAlinaghi S, Taj L, Mazaheri-Tehrani E, et al. HIV in Iran: onset, responses, and future directions. AIDS. 2021;35(4):529-42.

3. Sajadi L, Mirzazadeh A, Navadeh S, et al. HIV prevalence and related risk behaviours among female sex workers in Iran: results of the national biobehavioural survey, 2010. Sex Transm Infect. 2013;89(Suppl 3):iii37-iii40.

4. Sajadi L, Mirzazadeh A, Navadeh S, et al. HIV prevalence and related risk behaviours among female sex workers in Iran: results of the national biobehavioural survey, 2010. Sexually transmitted infections. 2013;89(Suppl 3):iii37-iii40.

5. Haeri S. Law of desire: Temporary marriage in Shi'i Iran: Syracuse University Press; 2014.

6. Karamouzian M, Baral S, Shokoohi M, et al. Incarceration among female sex workers in Iran: Findings of a nation-wide bio-behavioural surveillance survey in 2015. STI (under reivew). 2018.

7. Mirzazadeh A, Shokoohi M, Haghdoost A. The Iran Vulnerable Women's Study 2015, Regional Knowledge Hub, and WHO Collaborating Centre for HIV Surveillance. National FSW Survey Report2015.

8. Footer KH, Silberzahn BE, Tormohlen KN, Sherman SG. Policing practices as a structural determinant for HIV among sex workers: a systematic review of empirical findings. Journal of the International AIDS Society. 2016;19(4Suppl 3).

9. Shannon K, Strathdee SA, Shoveller J, Rusch M, Kerr T, Tyndall MW. Structural and environmental barriers to condom use negotiation with clients among female sex workers: implications for HIV-prevention strategies and policy. Am J Public Health. 2009;99(4):659-65. https:// doi.org/10.2105/ajph.2007.129858.

10. Strathdee SA, Abramovitz D, Lozada R, et al. Reductions in HIV/ STI incidence and sharing of injection equipment among female sex workers who inject drugs: results from a randomized controlled trial. PloS One. 2013;8(6):e65812.

11. Fahimfar N, Sedaghat A, Hatami H, Kamali K, Gooya M. Counseling and harm reduction centers for vulnerable women to HIV/ AIDS in Iran. Iran J Public Health. 2013;42(Supple1):98.

12. Karamouzian M, Nasirian M, Sedaghat A, Haghdoost AA. HIV in Iran. The Lancet. 2014;383(9922):1040.

13. Karamouzian M, Haghdoost AA, Sharifi H. Addressing the needs of sexual partners of people who inject drugs through 
peer prevention programs in Iran. Int J Health Policy Manag. 2014;2(2):81-3. https://doi.org/10.15171/ijhpm.2014.19.

14. Shokoohi M, Karamouzian M, Khajekazemi R, et al. Correlates of HIV testing among female sex workers in Iran: findings of a national bio-behavioural surveillance survey. PloS One. 2016;11(1):e0147587.

15. Dezhamkhooy M, Papoli-Yazdi L. Flowers in the garbage: transformations of prostitution in Iran in the late nineteenth-twenty-first centuries in Iran. Int J Hist Archaeol. 2020:1-23.

16. SA S, Taj L ME, S A-N, et al. HIV in Iran: epidemiology, response, challenges and way forward. AIDS. 2019; In press.

17. Sharifi H, Karamouzian M, Baneshi MR, et al. Population size estimation of female sex workers in Iran: Synthesis of methods and results. PloS One. 2017;12(8):e0182755.

18. Kazerooni PA, Sayadi M, Motazedian N, Sabet M. Sexual behaviors, knowledge and attitudes of female sex workers' towards HIV/ AIDS in Shiraz. Journal of health sciences and surveillance system. 2014;2(3):99-106.

19. Holmes KK, Levine R, Weaver M. Effectiveness of condoms in preventing sexually transmitted infections. Bull World Health Organ. 2004;82(6):454-61.

20. Weller SC, Davis-Beaty K. Condom effectiveness in reducing heterosexual HIV transmission. The Cochrane Library. 2002.

21. Jozani ZB, Seyedalinaghi S, Moayedi-Nia S, et al. Efficacy of a condom negotiation intervention among high risk iranian women in Tehran. Iran Journal of International Translational Medicine. 2018;6(3):105-12.

22. UNFPA, WHO, UNAIDS. Position statement on condoms and the prevention of HIV, other sexually transmitted infections and unintended pregnancy. 2015 Access at:http://www.unaids.org/ en/resources/presscentre/featurestories/2015/july/20150702_ condoms_prevention.

23. Andrews CH, Faxelid E, Sychaerun V, Phrasisombath K. Determinants of consistent condom use among female sex workers in Savannakhet, Lao PDR. BMC Womens Health. 2015;15(1):63.

24. Gu J, Bai Y, Lau JT, et al. Social environmental factors and condom use among female injection drug users who are sex workers in China. AIDS Behav. 2014;18(2):181-91.

25. Nishimura-Takahashi T, Akabayashi A, Kai I, Cabigon J, Ohi G, Naka K. Social and behavioral factors associated with condom use among female commercial sex workers (CSWs) in tarlac, the Philippines. Environ Health Prev Med. 1998;2(4):167-71.

26. Wang B, Li X, McGuire J, Kamali V, Fang X, Stanton B. Understanding the dynamics of condom use among female sex workers in China. Sex Transm Dis. 2009;36(3):134-40.

27. Gharehghani MAM, Irandoost SF, Soofizad G. Barriers to Condom use among female sex workers in Tehran, Iran: a qualitative study. Int J Women's Health. 2020;12:681-9.

28. Kerrigan D, Ellen JM, Moreno L, et al. Environmental-structural factors significantly associated with consistent condom use among female sex workers in the Dominican Republic. AIDS. 2003;17(3):415-23.

29. Urada LA, Morisky DE, Hernandez LI, Strathdee SA. Social and structural factors associated with consistent condom use among female entertainment workers trading sex in the Philippines. AIDS Behav. 2013;17(2):523-35.

30. Hao C, Guida J, Morisky DE, Liu H. Family network, workplace network, and their influence on condom use: a qualitative study among older female sex workers in China. The Journal of Sex Research. 2015;52(8):924-35.

31. Yang X, Xia G, Li X, Latkin C, Celentano D. Social influence and individual risk factors of HIV unsafe sex among female entertainment workers in China. AIDS Educ Prev. 2010;22(1):69-86.

32. Forouzan AS, Jorjoran Shushtari Z, Sajjadi H, Salimi Y, Dejman M. Social support network among people living with HIV/AIDS in Iran. AIDS research and treatment. 2013;2013.
33. Qiao S, Li XM, Stanton B. Social support and HIV-related risk behaviors: a systematic review of the global literature. AIDS Behav. 2014;18(2):419-41. https://doi.org/10.1007/ s10461-013-0561-6.

34. Shushtari ZJ, Hosseini SA, Sajjadi H, Salimi Y, Latkin C, Snijders TA. Social network and HIV risk behaviors in female sex workers: a systematic review. BMC Public Health. 2018;18(1):1020.

35. Hall VP. The relationship between social support and health in gay men with HIV/AIDS: an integrative review. J Assoc Nurses AIDS Care. 1999;10(3):74-86.

36. Roberts-Pittman B. An analysis of the social support network of gay men living with HIV: Indiana State University; 2005.

37. Hlebec V, Mrzel M, Kogovšek T. Social support network and received support at stressful events. Advances in Methodology \& Statistics/Metodoloski zvezki. 2009;5(1).

38. Marin A, Hampton KN, editors. Network instability in times of stability. Sociological Forum; 2019: Wiley Online Library.

39. Fitzpatrick R, Newman S, Lamb R, Shipley M. Social relationships and psychological well-being in rheumatoid arthritis. Soc Sci Med. 1988;27(4):399-403.

40. Sajjadi H, Shushtari ZJ, Shati M, et al. An indirect estimation of the population size of students with high-risk behaviors in select universities of medical sciences: A network scale-up study. PloS one. 2018;13(5):e0195364.

41. Bastani S. Middle class community in Tehran, social networks, social support and marital relationships: National Library of Canada $=$ Bibliothèque nationale du Canada; 2001.

42. Shati M, Haghdoost A, Majdzadeh R, Mohammad K, Mortazavi S. Social network size estimation and determinants in tehran province residents. Iran J Public Health. 2014;43(8):1079.

43. Zang C, Guida J, Sun Y, Liu H. Collectivism Culture, HIV Stigma and Social Network Support in Anhui, China: A Path Analytic Model. AIDS Patient Care \& STDs. 2014;28(8).

44. Wenzel SL, Green HD, Tucker JS, et al. The social context of homeless women's alcohol and drug use. Drug Alcohol Depend. 2009;105(1):16-23.

45. Latkin C, Knowlton A. Micro-social structural approaches to HIV prevention: a social ecological perspective. AIDS Care. 2005;17(S1):102-13.

46. Tucker JD, Peng H, Wang K, et al. Female sex worker social networks and STI/HIV prevention in South China. PloS one. 2011;6(9):e24816.

47. Yang H, Li X, Stanton B, et al. Condom use among female sex workers in China: role of gatekeepers. Sex Transm Dis. 2005;32(9):572.

48. Smith GL, Banting L, Eime R, O'Sullivan G, Van Uffelen JG. The association between social support and physical activity in older adults: a systematic review. Int J Behav Nutr Phys Act. 2017; 14(1):56.

49. Galea S, Ahern J, Vlahov D. Contextual determinants of drug use risk behavior: a theoretic framework. Journal of Urban Health: Bulletin of the New York Academy of Medicine. 2003;8(4).

50. J.Ramirez-Valles. the protective effects of community involvement for HIV risk behaviors: a conceptual framework. Health Education Research. 2002;17(4).

51. Fauk NK, Merry MS, Sigilipoe MA, Putra S, Mwanri L. Culture, social networks and HIV vulnerability among men who have sex with men in Indonesia. PloS One. 2017;12(6):e0178736.

52. Shushtari ZJ, Hosseini SA, Sajjadi H, Salimi Y, Latkin C, Snijders TA. Social network and HIV risk behaviors in female sex workers: a systematic review. BMC Public Health. 2018;18(1):1-16.

53. Wagner KD, Syvertsen JL, Verdugo SR, Molina JL, Strathdee SA. A mixed methods study of the social support networks of female sex workers and their primary noncommercial male partners in Tijuana. Mexico Journal of mixed methods research. 2018;12(4):437-57. 
54. Wenzel SL, Green HD Jr, Tucker JS, et al. The social context of homeless women's alcohol and drug use. Drug Alcohol Depend. 2009;105(1-2):16-23.

55. Wylie JL, Shah L, Jolly AM. Demographic, risk behaviour and personal network variables associated with prevalent hepatitis $\mathrm{C}$, hepatitis B, and HIV infection in injection drug users in Winnipeg. Canada BMC Public Health. 2006;6(1):1-19.

56. Chen Y, Li X, Shen Z, Zhou Y, Tang Z, Huedo-Medina TB. Contextual influence on condom use in commercial sex venues: A multi-level analysis among female sex workers and gatekeepers in Guangxi. China Social science research. 2015;52:124-31.

57. Miller M, Korves C, Fernandez T. The social epidemiology of HIV transmission among African American women who use drugs and their social network members. AIDS Care. 2007;19(7):858-65.

58. Needle RH, Coyle SL, Genser SG, Trotter R. Social networks, drug abuse, and HIV transmission. NIDA research monograph. $1995 ; 151$.

59. Heckathorn DD. Respondent-driven sampling: a new approach to the study of hidden populations. Soc Probl. 1997;44(2):174-99.

60. Crossley N, Bellotti E, Edwards G, Everett MG, Koskinen J, Tranmer M. Social network analysis for ego-nets: Social network analysis for actor-centred networks: Sage; 2015.

61. Shokoohi M, Karamouzian M, Mirzazadeh A, et al. HIV knowledge, attitudes, and practices of young people in Iran: findings of a national population-based survey in 2013. PloS One. 2016;11(9):e0161849.

62. Tom A, Bosker R. Multilevel analysis: an introduction to basic and advanced multilevel modeling. Stawski RS, editor. Los Angeles, CA.: Sage; 2012.

63. Lynn MR. Determination and quantification of content validity. Nursing research. 1986.

64. Polit DF, Beck CT. The content validity index: are you sure you know what's being reported? Critique and recommendations. Res Nurs Health. 2006;29(5):489-97.

65. Rubio DM, Berg-Weger M, Tebb SS, Lee ES, Rauch S. Objectifying content validity: Conducting a content validity study in social work research. Social work research. 2003;27(2):94-104.

66. Abdollahpour I, Nedjat S, Noroozian M, Majdzadeh R. Performing content validation process in development of questionnaires. Iran J Epidemiol. 2011;6(4):66-74.

67. Sijtsma K, Debets P, Molenaar IW. Mokken scale analysis for polychotomous items: theory, a computer program and an empirical application. Qual Quant. 1990;24(2):173-88.

68. Shushtari ZJ, Hosseini S, Sajjadi H, Salimi Y, Shahesmaeili A, Snijders T. Safe sex norm questionnaire for female sex workers: development and validation study in Iran. Public Health. 2018;164:82-90.

69. SeyedAlinaghi S, Paydary K, Kazerooni PA, et al. Evaluation of stigma index among people living with HIV/AIDS (PLWHA) in six cities in iran. Thrita. 2013;2(4):69-75.

70. Team RC. A language and environment for statistical computing. Vienna, Austria: R Foundation for Statistical Computing; 2012.

71. Bellhouse C, Crebbin S, Fairley CK, Bilardi JE. The impact of sex work on women's personal romantic relationships and the mental separation of their work and personal lives: a mixed-methods study. PloS One. 2015;10(10):e0141575-e. https://doi.org/10.1371/journal. pone. 0141575
72. Campbell C. Selling sex in the time of AIDS: the psycho-social context of condom use by sex workers on a Southern African mine. Soc Sci Med. 2000;50(4):479-94.

73. Simic M, Johnston LG, Platt L, et al. Exploring barriers to 'respondent driven sampling'in sex worker and drug-injecting sex worker populations in Eastern Europe. J Urban Health. 2006;83(1):6-15.

74. Busza J, Schunter BT. From competition to community: participatory learning and action among young, debt-bonded Vietnamese sex workers in Cambodia. Reprod Health Matters. 2001;9(17):72-81.

75. Zhao R, Wang B, Fang X, Li X, Stanton B. Condom use and selfefficacy among female sex workers with steady partners in China. AIDS Care. 2008;20(7):782-90.

76. Qiao S, Li X, Zhang C, Zhou Y, Shen Z, Tang Z. Social support and condom use among female sex workers in China. Health Care Women Int. 2015;36(7):834-50.

77. Li L, Wu S, Wu Z, Sun S, Cui H, Jia M. Understanding family support for people living with HIV/AIDS in Yunnan. China AIDS and Behavior. 2006;10(5):509-17.

78. Zhang X-D, Temmerman M, Li Y, Luo W, Luchters S. Vulnerabilities, health needs and predictors of high-risk sexual behaviour among female adolescent sex workers in Kunming. China Sex Transm Infect. 2013;89(3):237-44.

79. Sobo EJ. Finance romance, social support, and condom use among impoverished inner-city women. Hum Org. 1995:115-28.

80. Marcus RF, Swett B. Violence and intimacy in close relationships. J Interpers Violence. 2002;17(5):570-86.

81. Ford K, Wirawan D, Reed B, Muliawan P, Sutarga M. AIDS and STD knowledge, condom use and HIV/STD infection among female sex workers in Bali, Indonesia. AIDS Care. 2000;12(5):523.

82. Fageeh WM. Sexual behavior and knowledge of human immunodeficiency virus/aids and sexually transmitted infections among women inmates of Briman Prison, Jeddah, Saudi Arabia. BMC Infect Dis. 2014;14(1):290.

83. Lau JTF, Tsui HY, Siah P, Zhang K. A study on female sex workers in southern China (Shenzhen): HIV-related knowledge, condom use and STD history. AIDS Care. 2002;14(2):219-33.

84. Jorjoran Shushtari Z, Hosseini SA, Sajjadi H, Salimi Y, Shahesmaeili A, Snijders TA. HIV risk perception and sexual behaviors among female sex workers in Tehran. Iran Medical Journal of The Islamic Republic of Iran (MJIRI). 2019;33(1):608-14.

85. Afsar Kazerooni P, Sayadi M, Motazedian N, Sabet M. Sexual behaviors, knowledge and attitudes of female sex workers' towards HIV/AIDS in Shiraz. Journal of Health Sciences \& Surveillance System. 2014;2(3):99-106.

86. Lim S, Park JN, Kerrigan DL, Sherman SG. Severe food insecurity, gender-based violence, homelessness, and HIV risk among street-based female sex workers in Baltimore. Maryland AIDS and Behavior. 2019;23(11):3058-63.

Publisher's Note Springer Nature remains neutral with regard to jurisdictional claims in published maps and institutional affiliations. 


\section{Authors and Affiliations}

\section{Zahra Jorjoran Shushtari ${ }^{1}$ - Ali Mirzazadeh ${ }^{2,3} \cdot$ SeyedAhmad SeyedAlinaghi ${ }^{4} \cdot$ Seyed Ali Hosseini ${ }^{1} \cdot$ Homeira Sajjadi $^{5}$.} Yahya Salimi ${ }^{6} \cdot$ Tom A. B. Snijders ${ }^{7,8}$

1 Social Determinants of Health Research Center, University of Social Welfare and Rehabilitation Sciences, Tehran, Iran

2 Institute for Futures Studies in Health, HIV/STI Surveillance Research Center, and WHO Collaborating Center for HIV Surveillance, Kerman University of Medical Sciences, Kerman, Iran

3 Department of Epidemiology and Biostatistics, University of California San Francisco, San Francisco, CA, USA

4 Iranian Research Center, HIV/AIDS, Iranian Institute for Reduction of High-Risk Behaviors, Tehran University of Medical Sciences, Tehran, Iran
5 Social Welfare Management Research Center, University of Social Welfare and Rehabilitation Sciences, Tehran, Iran

6 Social Development \& Health Promotion Research Center, Health Institute, Kermanshah University of Medical Sciences, Kermanshah, Iran

7 Department of Sociology, University of Groningen, Groningen, Netherlands

8 Nuffield College, University of Oxford, Oxford, UK 